\title{
Application of Probiotics in Aflatoxins Risk Reduction in Foods: A Review
}

\author{
Atefeh Fooladi Moghaddam ${ }^{1}$, Zahra Sarlak ${ }^{1}$ and Hedayat Hosseini ${ }^{1,2 *}$ \\ ${ }^{1}$ Department of Food Sciences \& Technology, National Nutrition \& Food Technology Research Institute, Shahid Beheshti University of Medical Sciences, \\ Iran
}

${ }^{2}$ Food Safety Research Center, Shahid Beheshti University of Medical Sciences, Iran

Submission: October 28, 2019; Published: November 08, 2019

*Corresponding author: Hedayat Hosseini, Department of Food Technology, Faculty of Nutrition Sciences and Food Technology/National Nutrition and Food Technology Research Institute, Shahid Beheshti University of Medical Sciences, Tehran, Iran

\begin{abstract}
Mycotoxins are known to be harmful for human and animal health, as well as the economic and trade status. Among mycotoxins, aflatoxins are the most toxic that have been classified by IARC as group 1 carcinogens. Aflatoxins could contaminate a wide range of food commodities including corn, oilseeds, spices, and ground and tree nuts as well as milk, meat, and dried fruit. Since these toxins cannot be eliminated from foods and feeds, risk assessment is performed to estimate the risk and provide the regulators with management options. So far, all risk assessments emphasize on the point that in addition to regulatory measures, aflatoxins should be decontaminated from foods and feeds. Since physical and chemical strategies have downsides, probiotics have been suggested as the best strategy to reduce the risk of aflatoxins in foods. In this article, we review the new developments in reducing the risk of aflatoxins in foods using probiotics.
\end{abstract}

Keywords: Aflatoxins; Probiotic; Prebiotic; Risk; Food; Contamination

Abbreviations: HCC: Hepatocellular Carcinoma; CTTF: Chemical and Toxins Task force; DALYs: death and disability adjusted life years; WHO: World Health Organization; RASFF: Rapid Alert System for Food and Feed; EFSA: European Food Safety Authority; LAB: Lactic Acid Bacteria

\section{Introduction}

\section{Background}

Mycotoxins endanger human and animal health, hinder international trade, cause foods and feeds waste, and consume plenty of resources for conducting research, enforcing regulation, and finding solutions to reduce the problems they cause [1-3]. Moreover, in the livestock industry, they cause enormous economic cost as a result of decrease in animal growth, increase of feed consumption, and reduction of meat production [4].

Fungi belonging to the Aspergillus, Alternaria, Claviceps, Fusarium, Penicillium and Stachybotrys genera, primarily produce mycotoxins. They widely contaminate food and feed supplies, in the field or during storage [5-7]. Aspergillus and Penicillium species known as storage fungi, commonly grow on foods and feeds under storage conditions. However, Fusarium species often contaminate crops in the field and spread in the plant during growth [8].

Among mycotoxins, aflatoxins (AFs) are the most toxic with the biggest impact on human and animal health [4], and economic loss [3]. Therefore, controlling AFs contamination using effective technologies could potentially reduce such health risks and have significant benefits [9]. However, it is not always possible to control AF contamination totally. Therefore, identification of strate gies or elements that could be integrated into the human diet to reduce or prevent AFs toxicity would have a great potential in reducing the incidence of AFs-induced diseases [10].

There is a substantial body of scientific evidence regarding the importance of probiotic organisms for the maintenance of the balance of human intestinal microbiota, and their positive effect on host health. Ingestion of probiotics provides a beneficial effect on host organism in addition to inherent general nutrition [11] and keeps great promise for inhibition of the production of bacterial toxins. The latter effect is due to actions that inactivate the toxin and help with the removal of toxins from the body. This detoxification could occur by adsorption (binding toxins to their cell wall and decreasing the intestinal absorption of toxins), or as a result of metabolism of mycotoxins (e.g. AFs) by microorganisms [1113]. The aim of this article is to review the new developments in reduction of AFs risk in foods using probiotics.

\section{Importance of Aflatoxins in Health}

Contamination of food and feed supplies poses a worldwide challenge to food security and food safety. Every year, around 25\% of the world's harvested crops are contaminated by mycotoxins, causing huge agricultural and industrial losses of billions of dollars [14] as well as seriously impacting human and animal health [15-18]. 
AFs, of all mycotoxins, are considered the most toxic, with substantial economic burden to agriculture $[19,20]$. In the United States (US) and European Union (EU) countries, AFs are mainly an economic concern, whereas, in the developing countries of Asia and Africa, hundreds of hepatocellular carcinoma (HCC) cases each year result from AFs ingestion [19,21]. According to Williams et al. [22] 75\% of the world population and roughly 4.5 billion humans in developing countries are chronically exposed to AFs [22]. Chemical and Toxins Task force (CTTF) in 2010 reported that AFs are associated with the highest number of death and disability adjusted life years (DALYs) [23]. Moreover, the World Health Organization (WHO) estimated approximately 22000 (95\% UI 9000-57000) cases of AFs-related HCC in 2010 based on population attribution fraction [23].

[25]AFs induce toxicity and carcinogenicity in human and animal populations. The outcomes could be as severe as death in acute aflatoxicosis or triggering of more prolonged pathologic changes, including cancer and immunosuppression, nutritional interference and growth impairment in children in chronic aflatoxicosis [24]. The primary target organ is the liver, and the damage has been documented in rodents, poultry, and nonhuman primates after aflatoxin $\mathrm{B}_{1}\left(\mathrm{AFB}_{1}\right)$ intake. Acute aflatoxicosis has been shown in humans as acute hepatitis. Diet-related chronic low-level exposure to AFs is a risk factor for the development of HCC $[15,17]$. AFs is classified by the International Agency for Research on Cancer (IARC) in 2012 as group 1 carcinogen [25].

\section{Importance of Aflatoxins in Food}

There is a great body of reports regarding the occurrence of AFs in foods and feeds in many countries. The range of foods is wide from raw agricultural products including nuts, fruits, vegetables, herbs and spices contaminated with AFB1 exceeding the maximum permissible limit [26-28] to contamination with AFM1 in milk and milk products, including cheese and yogurt [29-31]. Apparently, AFs could affect a wide range of food commodities including corn, oilseeds, spices, and ground and tree nuts as well as milk, meat, and dried fruit [10].

Although it is highly desirable that food is not contaminated, the reality is that in parts of the world, food contamination with $\mathrm{AFs}$ is unavoidable due to their ubiquitous nature, especially in warm and humid conditions which is favourable for their growth and associated-mycotoxin production [32]. Moreover, unusual weather, insect pest damage, improper breeding and harvesting, or poor storage conditions could result in high levels of mycotoxins in crops and severe disease outbreaks [33].

Occurrence studies conducted during the last few years reported a relatively lower incidence of AFM1 in milk samples and milk products in European countries. However, in Asian and African counties, up to $100 \%$ of samples were contaminated by AFs [34]. The annual report of Rapid Alert System for Food and Feed (RASFF) of the European Union, showed AFs as the main hazard cited in EU border rejection [3].
AFs presented in foods could be bio-transformed in humans and excreted in human milk and urine. Once it presents in mother milk, it could be an exposure source for breastfed infants $[35,36]$.

Considerable information has been gathered concerning the health hazards of AFs exposure and conditions that lead to mold growth and AFs contamination during growing, harvesting and storage of crops [10]. Developing countries located in the tropical regions are at greatest risk, as most of these commodities are their staple food sources. Food insufficiency and lack of food diversity substantially increases the risk of exposure to AFs among individuals who live in these regions [24].

Elimination of AFs from foods is generally not possible. So, food regulators and scientists estimate the risk and potential harm that AFs exposure could cause towards human health using risk assessment. This would provide them with the information needed to decide on the best risk management options [33,37].

Joint FAO/WHO Expert Committee on Food Additives (JECFA) have performed risk assessment for some AFs in several sessions [38], and European Food Safety Authority (EFSA) also assessed their risk in foods and feeds [39]. Specific risk assessment has also been carried out in some countries. For example, in 2008, Shephard carried out a study in African countries that used carcinogenic potency and limited data on growth retardation and immune suppression as the end points. This study quantified the risk of HCC, immunosuppression, malnutrition and stunting in children exposed to AFs and emphasized again the importance of AFs risk management [37]. In 2019, Fooladi Moghaddam et al. [29] using carcinogenic potency showed that according to the current ML, the risk from $\mathrm{AFM}_{1}$ consumption in Iran is considered low, which is 10 -fold less than the risk range from $\mathrm{AFB}_{1}$ consumption set by the EU. However, the chronic effects of low-level exposure of AFs from different sources should be considered seriously [29]. In all these cases, the results showed AFs are among the most potent mutagenic and carcinogenic substances known and should be controlled in foods.

\section{Main Strategies for Aflatoxin Reduction}

Prevention of food and feed contamination with AFs is the best solution to eliminate AFs exposure in food. Therefore, pre-harvest and post-harvest strategies, including good agricultural practices and storage conditions should be put in place $[40,41]$. But in most cases, is not possible to prevent food contamination with AFs. In order to decontaminate foods and feeds containing AFs, many physicochemical technologies have been suggested to eliminate, inactivate or reduce the bioavailability of AFs, including, chemical, physical and biological methods [42]. Neither chemical nor physical approaches are cost effective. Moreover, removal of the toxins is not enough and there might be nutritional losses as well as unwanted changes in food properties, such as diminishing the safety and sensory quality, and insufficient applicability and practicability [43]. Thus, other novel biological methods could be used to inhibit mold growth and introduce a binding agent to AFs. 
AFs degradation abilities of many bacteria, yeast and fungi have been shown by scientists in many studies.

In a study conducted by Ciegler et al. [44] a 100\% detoxification of the toxin by bacteria was reported in contaminated milk, oil, peanut butter, peanuts and corn; however, contaminated soybean was partially detoxified [44].

The use of probiotic strains, especially lactic acid bacteria (LAB) has been suggested. Probiotic intake not only has a beneficial effect on the host organism beyond general nutritional properties, but it also seems promising in reducing the bioavailability of consumed AFs [45].

\section{Application of Probiotics for Contaminant Reduction}

Using bacteria to either block the uptake of AFs in the human intestinal track or reduce their risk in a comparative way was the focus of scientists for many years. These bacteria could be the normal gut flora or present in fermented foods we eat. A large portion of the normal gut flora contains Bifidobacterium which provides many probiotic effects that are increasingly used in fermented dairy products [12].

The competition for nutrients between bacterial cell and fungi leads to decrease in mold growth and AFs production. Moreover, environmental settings and the fungi strain influence binding of AFs [46]. Wacco et al. [47] showed that fermentation could be used to enrich the food with probiotics and contribute to reducing the risk of AFs in maize products that are consumed as staple foods in sub-Saharan Africa. They also reported the positive consumer acceptability regarding flavour profile, and sensorial properties of the product [47].

These findings support strategies that certain novel probiotic bacteria with high AFs binding capacity could be used for detoxification of foods [48].

\section{Factors affecting the binding of AFs to bacterial cell}

\section{Heat and acid treatment of probiotic bacteria}

Pierides et al. [49] reported that heat inactivation remarkably improved the $\mathrm{AFM}_{1}$ removal capability of all strains (L. rhamnosus GG, L. rhamnosus LC-705, L. rhamnosus $1 / 3$, L. gasseri ATCC 33323 and L. acidophilus LA1) except for L. lactis ssp. cremoris ARH 74 which showed no significant difference between the binding ability of viable and boiled non-viable cells from phosphate buffer saline (PBS) after 15-16h [49]. In a similar study, the heatkilled bacteria (L. rhamnosus GG and L. rhamnosus LC-705) effectively removed $\mathrm{AFB}_{1}$ from liquid media after $4 \mathrm{~h}$ (19 and 18\% residue left, respectively). This was statistically significant when compared with removal percentages of precultured (23 and 25\% residue left, respectively) and freeze-dried bacteria (35 and 50\% residue left, respectively) [50]. In a study conducted by Kabak and Var, six probiotic strains (L. acidophilus NCC12, L. acidophilus NCC36, L. acidophilus NCC 68, B. bifidum Bb 13, B. bifidum NCC 381 and L. rhamnosus) were inoculated in PBS and reconstituted milk containing 5, 10 and $20 \mathrm{ppb} \mathrm{AFM}_{1}$ and were incubated for 0,4 and $24 \mathrm{~h}$ at $37^{\circ} \mathrm{C}$. The binding abilities of $\mathrm{AFM}_{1}$ by viable and heatkilled bacteria in PBS ranged from 10.22 to $26.65 \%$, and 14.04 to $28.97 \%$, respectively. Similarly, the range of $\mathrm{AFM}_{1}$ reduction in reconstituted milk was $7.85-25.94 \%$ for viable and $12.85-27.31 \%$ for heat-killed bacteria after $4 \mathrm{~h}$ [51]. Furthermore, Sarlak et al. [52] showed that treatment of doogh (Iranian fermented milk drink) with heat-killed L. acidophilus LA-5 had a higher aflatoxin $\mathrm{M}_{1}\left(\mathrm{AFM}_{1}\right)$ removal ability compared to viable bacteria on the first day of storage [52].

It has been suggested that in decontamination of AFs by LAB, physical adhesion to the bacterial cell-wall components such as polysaccharides and peptidoglycans is more efficient than covalent binding or degradation by bacteria metabolism [53].

Polysaccharides and peptidoglycans are supposed to be considerably affected by heat treatment, which could cause denaturation of proteins, in turn increasing the hydrophobic nature of the surface or forming products of a Maillard reaction between polysaccharides and peptides and proteins. These disturbances allow AFs to bind to the bacterial cell wall and plasmatic membrane components, which are unavailable when the cell wall is intact [54].

However, in the study conducted by Sarlak et al. [52] free AFM reduction was significantly enhanced in treatment with viable $L$. acidophilus at days 14 and 28. Viable inoculated probiotic bacteria have reproduction activity during fermentation and refrigerated storage. This could be responsible for increases in both live and dead cell populations. Finally, viable L. acidophilus bacteria exhibited higher $\mathrm{AFM}_{1}$ removal compared to heat-killed bacteria in doogh after 4 weeks. Meanwhile, the use of viable probiotics exploits health benefit and therapeutic effects of probiotics [52].

Haskard et al. [54] reported that acid and heat treatment have a significant impact on both the amount of $\mathrm{AFB}_{1}$ bound and its retention after washing for all strains (L. rhamnosus GG, L. rhamnosus LC-705, L. acidophilus LC1, L. lactis subsp. lactis, L. acidophilus ATCC 4356, L. plantarum, L. casei Shirota, L. delbrueckii subsp. bulgaricus, L. helveticus, P. freudenreichii subsp. shermanii JS, Lactococcus lactis subsp. cremoris and Streptococcus thermophilus). Also, they found out the higher effectiveness of acid treatment compared to heat treatment [54]. These results are in agreement with Azab et al. [55] who observed that $\mathrm{AFB}_{1}$ removal capacity by $L$. acidophilus, L. casei, L. helveticus and L. bulgaricus became higher when using acid treatment (43.10-87\%) and thermal treatment (28.5-71.9\%) compared with buffer solution (16.3-56.6\%) [55]. Binding of $\mathrm{AFB}_{1}$ is expected to be greatly extracellular by both viable and heat-treated bacteria. Probably, acid treatment causes more intracellular binding [56]. Acid may break the glycosidic links of polysaccharides and amide linkages of proteins. Hence, acid treatment breaks down the peptidoglycan structure of the bacterial cell wall. In spite of the fact that the peptidoglycan layer is quite thick in these microorganisms, acid may decrease thickness and cross-links and result in larger pore sizes and more 
pores. This perturbation of the bacterial cell may allow $\mathrm{AFB}_{1}$ to bind to the cell wall and plasma membrane constituents that are not available when the bacterial cell wall is not damaged [54].

Hydrophobic groups (polysaccharide especially $\beta$-D-glucan, peptidoglycan and teichoic) take part in binding to AFs. Acid treatment, as well as heat treatment, lead to exposure of more hydrophobic agents on the surface of bacteria. Therefore, all these results confirm that bacterial viability is not a prerequisite in the detoxification of AFs.

\section{Presence of salts}

Metal ions slightly decrease binding capacity due to the effect of these molecules on the bacterial surface charge as well as electrostatic interactions, which have been suggested to have a minor effect on the detoxification of AFs. Therefore, binding diminishes in the presence of salts depending on their concentration. In the study carried out by Lahtinen, when bacteria were incubated with chelating agents such as EDTA and EGTA to remove metal ions bound to the bacterial surface, the similarity in binding properties of the samples with and without chelating agents, indicates lack of involvement of $\mathrm{Ca}^{+2}$ or $\mathrm{Mg}^{+2}$ in $\mathrm{AFs}$ binding. Furthermore, binding of AFs by probiotic bacteria was predominantly lower in the presence of divalent ions $\left(\mathrm{Ca}^{+2}\right)$ than in the presence of monovalent ions $\left(\mathrm{Na}^{+}\right)$[57]. In other words, chelating of metal ions by the $\beta$-dicarbonyl moiety of AFs may influence their binding by LAB $[56,58]$.

\section{Effect of bile on aflatoxins binding}

Previous data showed that bile salts are able to improve binding ability of bacteria with three mechanisms:

a) altering the expression of lactobacilli gens, which results in encoding of more new proteins on the cell envelope [59,60],

b) altering the architecture of bacterial cell surface as well as the conformation of cell wall components (e.g. proteins, glycolipids and phospholipids) that cause the new sites for AFs binding [61-64] and

c) increasing relative solubility of AFs and allowing for further interactions with macromolecules such as cell wall components of bacteria in solution [65].

\section{Treatment with enzymes}

The role of cell wall proteins and glycoproteins was further investigated by treatment of LAB with specific and non-specific proteolytic enzymes. Site-specific proteolytic enzymes such as trypsin and $\alpha$-chymotrypsin were used to cleave proteins at different sites. Results demonstrated that binding properties of untreated bacteria are similar to trypsin or $\alpha$-chymotrypsin-treated bacteria and proposed that these enzymes do not remarkably affect binding sites. Hence, the binding site is unlikely to contain the peptide fragments cleaved at positively charged amino acids or hydrophobic amino acids, which are the preferred substrates for trypsin and $\alpha$-chymotrypsin, respectively [57]. While non-specific proteo- lytic enzymes such as pronase E produced greater fragmentation of protein and presumed to be responsible for the significant effect on the capability of removing AFs [58].

The possible role of N-linked glycans was also investigated. $\mathrm{N}$-linked glycans are often found on the bacterial surface and are well known to play a role in bacterial adhesion and in intercellular interactions [66]. N-glycosidase F cleaves asparagine bound $\mathrm{N}$-linked glycans, hydrolysing the glycosylamine linkage of most $\mathrm{N}$-linked glycoproteins and releasing a 1-amino oligosaccharide. Exposure of probiotic bacteria with $\mathrm{N}$-glycosidase $\mathrm{F}$ did not affect $\mathrm{AFB}_{1}$ binding. Therefore, AFs are unlikely to bind to the 1-amino oligosaccharide part of an asparagine bound N-linked glycoprotein [57]. Additionally, treatment with lipase did not cause a notable decrease in AFs binding, suggesting that collaboration of lipids (such as lipoteichoic acid) could be unexpected [58].

\section{Effect of exopolysaccharide (EPS)}

Exopolysaccharides, teichoic or lipoteichoic acids and peptidoglycans are major types of carbohydrates in the bacterial cell wall [64]. It is known that some LABs such as L. rhamnosus GG, L. reuteri and L. casei shirota produce EPS [67], which is liberated into the surrounding media but also loosely adheres to the bacteria and forms an amorphous layer outside of the cell wall peptidoglycan. The EPS isolated from L. rhamnosus GG showed no $\mathrm{AFB}_{1}$ binding ability and the bacteria which EPS had been removed from maintained their potential for binding to $\mathrm{AFB}_{1}$ [57]. Similarly, Hernandez-Mendoza demonstrated that cell-bound EPS extracted from L. reuteri and L. casei shirota had a rather limited capacity for binding to $\mathrm{AFB}_{1}$ [68]. These results strongly exhibit the low binding activity by EPS $[57,68]$.

\section{Treatment with anti-hydrophobic and carbohydrate oxida- tion agents}

It was investigated that after adding anti-hydrophobic agents such as urea, binding capacity diminished, especially for non-viable bacteria due to the exposure of more hydrophobic sites in them by acid or heat treatment $[57,58]$. Meanwhile, treatment with carbohydrate oxidation agents such as periodate causes oxidation of $\mathrm{cis} \mathrm{OH}$ groups to aldehydes and carbon acid groups and significantly decreases the binding capacity of AFs by LAB. Although periodate affects mainly carbohydrates, C-C bounds of some polar amino acids are also susceptible of oxidation cleavage [58]. Generally, the bacterial cell wall polysaccharides (polysaccharide, peptidoglycan and teichoic) are considered to be hydrophobic agents and take part in the detoxification of AFs $[54,58]$.

\section{Fermentation}

Generally, fermentation could reduce the amount of free AFs in three ways:

a) Structural decomposition of AFs due to low $\mathrm{pH}$ and the biological activity of starter microorganisms

Govaris et al. [69] reported that reduction of $\mathrm{AFM}_{1}$ was high- 
er in yoghurts with a pH of 4.0 than in yoghurts with a pH of 4.6 during fermentation and refrigerated storage [69]. This phenomenon attributed to further metabolic activity of LAB and production of larger amounts of lactic acid and other fermentation by-products along with the lower $\mathrm{pH}$. Some studies have showed variable transformation of $\mathrm{AFB}_{1}$ and $\mathrm{AFM}_{1}$ into their hydroxy derivative $\mathrm{AFB}_{2 \mathrm{a}}$ and $\mathrm{AFM}_{2 \mathrm{a}}$ in fermented dairy products. This transformation after fermentation is variable, and acidity was responsible for these conversions. These new compounds $\left(\mathrm{AFB}_{2} \mathrm{a}, \mathrm{AFM}_{2} \mathrm{a}\right.$ and aflatoxicols) are not toxic or less toxic $[70,71,56]$. On the contrary, in a study performed by Sarlak et al. [52] the samples of probiotic doogh with a final fermentation $\mathrm{pH}$ of 4.5 detoxified more free $\mathrm{AFM}_{1}$ during fermentation and storage than those with a $\mathrm{pH}$ of 4.2, due to the higher viability of yoghurt cultures and/or probiotics [52].

\section{b) Increasing binding capacity of AFs to milk proteins} due to changes in their structure made by $\mathrm{pH}$ reduction and acid formation

Fermentation with a decrease in $\mathrm{pH}$ denatures the structure of milk proteins such as caseins, leading to formation of a network yoghurt (or doogh) coagulum that holds the AFs inside the precipitate [72,73]. Moreover, the complex casein fractions with denatured whey proteins lead to the exposure of further hydrophobic sites [74] that could bind to greater AFs. However, researchers have reported controversial results on the fate of AFs in yoghurts. Blanco et al. [75] and Wiseman \& Marth [76] reported that aflatoxins did not change in yoghurt after fermentation [75,76]. In contrast, Munksgaard et al. [77] and Van Egmond et al. [78] reported a slight increase in the concentration of $\mathrm{AFM}_{1}$ in yoghurt after fermentation $[77,78]$. Such different results in the stability of AFs during manufacture and storage of yoghurts might be due to several factors, including different final fermentation $\mathrm{pHs}$ of yoghurts, various initial concentrations of starter bacteria and AFs in the milk, different fermentation conditions, changes in physicochemical properties of caseins and/or application of unreliable analytical methods.

\section{c) Binding of AFs to the bacteria cell}

Several studies have investigated the effect of different types of Lactobacillus spp. on AFs levels in fermented products such as yogurt, kefir or milk and have determined the reduction rate of AFs during fermentation and storage of such products alone and in the presence of certain LAB strains. The effect of traditional starter cultures was alone investigated on AFs by Sarimehmetoglu \& Küplülü [79]; and Khoury et al. [80] Sarimehmetoglu \& Küplülü showed that Streptococcus thermophilus ST-36 has a higher binding ability in comparison to Lactobacillus delbrueckii subsp. bulgaricus $\mathrm{CH}-2$ in reconstituted milk. However, the binding abilities may decrease because of synergetic properties of two microorganisms in yoghurt [79]. In another study performed by Khoury et al. [80] $\mathrm{AFM}_{1}$ binding of Lactobacillus bulgaricus in yogurt after 2 and $6 \mathrm{~h}$ was $40 \%$ and $58.5 \%$, respectively. Whereas, Streptococcus thermophilus showed lower binding ability (22.6\% removal after
$2 \mathrm{~h}$ and $37.7 \%$ at $6 \mathrm{~h}$ ) during yogurt processing. Moreover, a combined culture of Lactobacillus bulgaricus and Streptococcus thermophilus bind $29.3 \%$ and $46.7 \%$ within $2 \mathrm{~h}$ and $6 \mathrm{~h}$ of incubation, respectively [80]. Some studies compared reduction of free AFs by only starter cultures and by both starter cultures and probiotic bacteria. Elsanhoty et al. [81] investigated the reduction rate of $\mathrm{AFM}_{1}$ level during the processing and storage of yogurt (alone), yogurt with L. plantarum, and yogurt with L. acidophilus. The degradation levels of $\mathrm{AFM}_{1}$ in these products were $61.4 \%, 89.9 \%$, and $84.8 \%$ respectively [81]. In the study conducted by Sarlak et al. [52] free $\mathrm{AFM}_{1}$ reduction levels were approximately $39 \%$ in doogh (alone) and approximately 95\% in the presence of L. acidophilus. Barukcic et al. reported the same result about yogurt and kefir cultures. They observed that in all treatments, the probiotic cultures were more effective. In their study, the kefir starter alone was the least efficient in all tested cultures and L. casei was recognized as the most efficient strain, achieving a reduction level of approximately 58\% [52]. It seems that starter culture alone has less impact on AFs level compared to Lactobacillus strains or it may not even have a significant reduction effect on their level. However, Sani et al. [82] reported a different result for kefir culture. They observed that the reduction rate of $\mathrm{AFM}_{1}$ in kefir with kefir culture alone (85\%) was more than the fermented milk by combination of kefir culture and L. casei $(81.76 \%)$ and also fermented milk by L.casei (69.19\%) [82].

\section{Initial AFs concentration}

Several studies have investigated the correlation between the initial concentration levels of AF and its reduction rate. However, they have reported different and even contradictory results. In a study carried out by Kabak \& Var [51], they found no significant correlation between the initial concentration and reduction of $\mathrm{AFM}_{1}$ levels in contaminated PBS. The most efficient binder, $B$. bifidum Bb13 removed 23.48, 26.62, and $24.77 \%$ of $\mathrm{AFM}_{1}$ at 5,10 and $20 \mathrm{ppb}$, respectively within $0 \mathrm{~h}$ [51]. This finding is similar to that of El-Nezami et al. who reported that the removal of $\mathrm{AFB}_{1}$ did not increase significantly by the increasing concentration of $\mathrm{AFB}_{1}$ [51]. Abbes et al. evaluated $\mathrm{AFM}_{1}$ binding ability of two strains of L. rhamnosus and L. plantarum in three levels of initial $\mathrm{AFM}_{1}$ and three incubation times $(0 \mathrm{~h}, 6 \mathrm{~h}, 24 \mathrm{~h})$. They reported binding abilities of $85.8 \%, 90.7 \%$ and, $95.1 \%$ for L. rhamnosus and $72.3 \%$, $72.9 \%$, and $76.9 \%$ for L. plantarum in $\mathrm{AFM}_{1}$ concentrations of $0.05,0.1$, and $2 \mu \mathrm{g} / \mathrm{l}$, respectively [83]. Adibpour et al. [84] also observed that the binding ability of LAB strains increased by increasing initial $\mathrm{AFM}_{1}$ concentration [84]. However, Ismail et al. found that $\mathrm{AFM}_{1}$ binding potential of LAB strains in lower initial concentration levels was more than their $\mathrm{AFM}_{1}$ binding ability in higher concentration levels of $\mathrm{AFM}_{1}$ [85]. These contradictions may be described by the differences in experimental conditions and procedures.

\section{Amount of inoculation}

Some studies show that bacteria population is one of the important factors in the removal of AFs by lactobacilli and bifidobac- 
teria. El-Nezami et al. [86] reported that minimally $2 \times 10^{9} \mathrm{cfu} /$ $\mathrm{ml}$ cells were required for significant $\mathrm{AFB}_{1}$ removal [51]. Similarly, Line and Brackett demonstrated that approximate viable cell populations of $1 \times 10^{9} \mathrm{cfu} / \mathrm{ml}$ or greater were required for significant removal of $\mathrm{AFB}_{1}$ [86].

Kabak \& Var [51] reported that removal of $\mathrm{AFM}_{1}$ by the viable probiotic bacteria with $8 \log \mathrm{cfu} / \mathrm{ml}$ ranged from 10.22 to $26.65 \%$ depending on the contamination level and incubation time, while the binding ability dropped to $0-5.02 \%$ when the level of inoculated probiotic cells was 7log cfu/ml [51]. Ismail et al. [85] found that the population of bacteria is also very important in the potential of the heat treated-bacteria. They observed that the reduction rate from about $30 \%$ in $10^{8} \mathrm{cfu} / \mathrm{ml}$ depending on the bacteria type enhanced to about $80 \%$ or even $100 \%$ (for L. helveticus) in the concentration of $10^{10} \mathrm{cfu} / \mathrm{ml}$ [85]. Sarlak et al. [52] reported the ability of viable L. acidophilus for binding to $\mathrm{AFM}_{1}$ in doogh with the population of $10^{7} \mathrm{cfu} / \mathrm{ml}$ and $10^{9} \mathrm{cfu} / \mathrm{ml}$ as $95.2 \%$ and $99 \%$, respectively after 28 days. According to this research, doogh treatment with the amount of inoculation 100 times more than treatment with $7 \log \mathrm{cfu} / \mathrm{ml}$ L. acidophilus only reduced $3.8 \%$ more $\mathrm{AFM}_{1}$, which appears not to be cost-effective [52].

\section{Combination of time and temperature}

According to some studies, removal of AFs is a rapid process with no significant difference between different incubation periods at all levels of AFs. For example, Kabak \& Var [51] indicated that viable $L$. acidophilus NCC36 $\left(10^{8} \mathrm{cfu} / \mathrm{ml}\right)$ removed $22.23,23.47$ and $22.24 \%$ of $\mathrm{AFM}_{1}$ from buffer solution containing 5ppb, within 0, 4 and 24h, respectively [51]. This study agrees with El-Nezami et al. [50] who reported that no remarkable difference was observed between different incubation periods in the reduction of $\mathrm{AFB}_{1}$ from $\mathrm{PBS}$ by $\mathrm{LAB}$ and bifidobacteria [50]. On the contrary, Peltonen et al. [87] demonstrated that the $\mathrm{AFB}_{1}$ binding of L. amylovorus CSCC 5160 was enhanced significantly during incubation from $52.6 \%(0 \mathrm{~h})$ to $73.2 \%(72 \mathrm{~h})$ [87]. Also, Abbes et al. [83] compared the effect of different incubation times ( $0 \mathrm{~h}, 6 \mathrm{~h}$, and $24 \mathrm{~h})$ on the removal of $\mathrm{AFM}_{1}$. They revealed a direct correlation between incubation time and eliminating AFs as they observed an increase of about $60-70 \%$ from $0 \mathrm{~h}$ to $24 \mathrm{~h}$ depending on the bacteria type and initial AFs concentrations [83]. Some papers evaluated the effect of different storage time and revealed similar results. These studies found that binding percentages of different strains of Lactobacillus spp. increased during the storage period as the most extensive reduction was observed at the end of the storage period. Elsanhoty et al. [81] found an increase of $\mathrm{AFM}_{1}$ reduction of about $45 \%$ and $56 \%$ for L. acidophilus and $L$. plantarum, respectively after 7 days storage of yogurt [81]. Sarlak et al. [52] compared the binding potential of heat-killed bacteria and viable bacteria during the storage time in doogh. The results showed that the increase of storage time was more effective on the binding potential of viable bacteria than heat-killed bacteria. They found that the reduction rate significantly increased at days 14 and 28 compared to the first day in both groups [52] Howev- er, Adibpour et al. [84] investigated the AFM 1 binding ability of $L$. acidophilus strain in the presence and absence of yogurt starter culture and yogurt starter culture alone during the storage period of 21 days in the refrigerator. They observed a degradation percentage of over $90 \%$ in $\mathrm{AFM}_{1}$ level in all groups on the first day of storage and no significant increase in degradation levels was observed during the storage time [84].

\section{Washing and stability of binding}

The stability of the bound between probiotics and AFs was assessed through washing with buffer solutions. In most studies, binding between cells and AFs were assumed to be unstable based on the results of washing tests. For example, all strains in the study of Haskard et al. [54]. showed reversible binding of $\mathrm{AFB}_{1}$ when washed with water. There was significant difference in the percentage of $\mathrm{AFB}_{1}$, bound both initially and after up to five washes. Of all the strains, L. rhamnosus GG and L.rhamnosus LC-705 were most effective in initially binding and also retaining $\mathrm{AFB}_{1}$, suggesting that the complexes of AFs with these strains were the most stable [54]. The results agree with Peltonen et al. [87] who observed that $\mathrm{AFB}_{1}$ was not bound strongly by the lactobacilli strains, and that bound $\mathrm{AFB}_{1}$ was released in the range of 27.894.4\% into the solution [87].

Similarly, in the study performed by Ismail et al. [85] most strains of $\mathrm{LAB}$ resulted in the release of $\mathrm{AFM}_{1}$, while only a few strains released AFs in the 3rd washing. Lactobacillus lactis-aflatoxin complex formed in 0.05 and $0.1 \mathrm{ppb}$ spiked $\mathrm{AFM}_{1}$ milk samples was found most stable among all the tested microbes and released only $19.5 \%$ and $34.8 \% \mathrm{AFM}_{1}$, respectively [85]. However, Kabak \& Var [51] observed that binding was approximately irreversible and $\mathrm{AFM}_{1}$ were slightly released back into the buffered solution. After washing of the bacteria-aflatoxin complexes, 5.628.54\% $\mathrm{AFM}_{1}$ were released back into the solution [51]. Serrano-Nino et al. [65] concluded that the aflatoxin was released easily due to the weak nature of non-covalent bonds between the toxin and bacteria and binding differences between strains and bound stability are due to the differences in their cell walls [65].

\section{Conclusion}

There is no doubt about the intensity of the risk of AFs regarding human health, food safety, and economic losses. As a risk reduction strategy, probiotics could be used due to their ability to alleviate AFs in food and in the human gut, as well as deliver other health benefits to consumers.

The results of this review indicated that different probiotic starters uniquely affect flavor profile, sensorial properties and ultimately, acceptability. Most of the strains of LAB are able to bind to AFs molecules. Different factors such as fermentation conditions, storage period, bacteria population, type of culture and viability of bacteria could remove free AFs - from both contaminated dairy products and PBS. The influence of these factors exerts due to binding of AFs to food components (such as starter bacterial cells as well as milk proteins) or their structural modifications. 
Some studies indicated that absorption of probiotic-aflatoxin and/or probiotic- protein complexes in the gastrointestinal tract decreases.

There are varieties of responses between different probiotics against AFs.

All in all, till now, evidence-based studies suggested no single strategy as the final solution for AFs decontamination and risk reduction in foods. However, there are so many studies supporting the microbial decontamination as the most suitable solution. Thus, application of microorganisms as the best solution to the current problem of AFs contamination needs to be seriously evaluated from a food safety and nutritional point of view.

\section{References}

1. Hussein HS, Brasel JM (2001) Toxicity, Metabolism, and Impact of Mycotoxins on Humans and Animals. Toxicology 167(2): 101-134.

2. Stoev SD (2013) Food safety and increasing hazard of mycotoxin occurrence in foods and feeds. Crit Rev Food Sci Nutr 53(9): 887-901.

3. Alshannaq A, Yu JH (2017) Occurrence, Toxicity, and Analysis of Major Mycotoxins in Food. Int J Environ Res Public Health 14(6): 632.

4. Fan Y, Zhao L, Ji C, Li X, Jia R, et al. (2015) Protective Effects of Bacillus Subtilis ANSB060 on Serum Biochemistry, Histopathological Changes and Antioxidant Enzyme Activities of Broilers Fed Moldy Peanut Meal Naturally Contaminated with Aflatoxins. Toxins 7(8): 3330-3343.

5. IARC (2002) International Agency for Research on Cancer monographs on the evaluation of carcinogenic risks to humans: Some traditional herbal medicines, some mycotoxins, naphthalene and styrene. in Expert opinion of an IARC Monographs on the Evaluation of Carcinogenic Risks to Humans. Lyon, France: World Health Organization, International Agency for Research on Cancer.

6. Milićević, D, Škrinjar M, Baltić T (2010) Real and Perceived Risks for Mycotoxin Contamination in Foods and Feeds: Challenges for Food Safety Control. Toxins 2: 572-592.

7. Omaye ST (2004) Chapter 13/ Fungal Mycotoxins. In: Food and Nutritional Toxicology. CRC Press LLC: United States of America. pp. 204212.

8. Bennett JW, Klich M (2003) Mycotoxins. Clin Microbiol Rev 16(3): 497516.

9. Khlangwiset P, Wu F (2010) Costs and Efficacy of Public Health Interventions to Reduce Aflatoxin-induced Human Disease. Food Addit Contam Part A Chem Anal Control Expo Risk Assess 27(7): 998-1014.

10. Magnussen A, Parsi MA (2013) Aflatoxins, Hepatocellular Carcinoma and Public Health. World J Gastroenterol 19(10): 1508-1512.

11. Markowiak P, Śliżewska K (2017) Effects of Probiotics, Prebiotics, and Synbiotics on Human Health. Nutrients 9(9): 1021.

12. Oatley JT, Rarick MD, Ji GE, Linz JE (2000) Binding of Aflatoxin B1 to Bifidobacteria in Vitro. J Food Prot 63(8): 1133-1136.

13. Joint FAO/WHO Expert Consultation (2001) Evaluation of Health and Nutritional Properties of Probiotics in Food including Powder Milk with Live Lactic Acid Bacteria, in Probiotics in foods: Health and nutritional properties and guideline for evaluation. Rome.

14. Marin S, Ramos AJ, Cano-Sancho G, Sanchis V (2013) Mycotoxins: Occurence, Toxicology, Expousure Assessment. Food and Chemical Toxicology 60: 218- 237.

15. Kensler TW, Roebuck BD, Wogan GN, Groopman JD (2011) Aflatoxin: A 50-year Odyssey of Mechanistic and Translational Toxicology. Toxico- logical Sciences 120(suppl-1): S28-S48.

16. Udomkun P, Wiredu AN, Nagle M, Müller J, Vanlauwe B, et al. (2017) Innovative Technologies to Manage Aflatoxins in Foods and Feeds and the Profitability of Application - A Review. Food Control 76: 127-138.

17. Frantisek M, Ostry V, Grosse Y, Roubal T, Skarkova J, et al. (2006) Monitoring the Mycotoxins in Food and Their Biomarkers in the Czech Republic. Mol Nutr Food Res 50(6): 513-518.

18. Wild CP, Gong YY (2010) Mycotoxins and Human Disease: a Largely Ignored Global Health Issue. Carcinogenesis 31(1): 71-82.

19. Mitchell NJ, Bowers E, Hurburgh C, Wu F (2016) Potential Economic Losses to the US Corn Industry from Aflatoxin Contamination. Food Addit Contam Part A Chem Anal Control Expo Risk Assess 33(3): 540550 .

20. Ostry V, Malir F, Toman J, Grosse Y (2017) Mycotoxins as Human Carcinogens-the IARC Monographs Classification. Mycotoxin Research 33(1): 65-73.

21. Liu Y, Wu F (2010) Global Burden of Aflatoxin-Induced Hepatocellular Carcinoma: A Risk Assessment. Environmental Health Perspectives. 118(6): 818-824.

22. Williams JH, Phillips TD, Jolly PE, Stiles JK, Jolly CM, et al. (2004) Human Aflatoxicosis in Developing Countries: a Review of Toxicology, Exposure, Potential Health Consequences, and Interventions. Am J Clin Nutr 80(5): 1106-1122.

23. Gibb H, Devleesschauwer B, Bolger PM, Wu F, Ezendam J, et al. (2010) World Health Organization Estimates of the Global and Regional Disease Burden of 'Four Foodborne Chemical Toxins: A Data Synthesis. F1000Research 4: 1393.

24. Strosnider H, Azziz-Baumgartner E, Banziger M, Bhat RV, Breiman R et al. (2006) Workgroup Report: Public Health Strategies for Reducing Aflatoxin Exposure in Developing Countries. Environmental Health Perspectives 114(12): 1898-1903.

25. IARC (2012) International Agency for Research on Cancer monographs on the evaluation of carcinogenic risks to human. in Expert opinion of an IARC Monographs on Cancer monographs on the evaluation of carcinogenic risks to human. Lyon, France: World Health Organization, International Agency for Research on Cancer.

26. Chen YC, Liao CD, Lin HY, Chiueh LC, Shih DYC (2013) Survey of Aflatoxin Contamination in Peanut Products in Taiwan from 1997 to 2011. Journal of Food and Drug Analysis 21(3): 247-252.

27. Guchi E (2015) Implication of Aflatoxin Contamination in Agricultural Products. American Journal of Food and Nutrition 3(1): 12-20.

28. Waliyar F, Osiru M, Ntare BR, Kumar KVK, Sudini H, et al. (2014) Post-harvest Management of Aflatoxin Contamination in Groundnut. World Mycotoxin Journal 8(2): 245-252.

29. Fooladi Moghaddam A, Rychlik M, Hosseini H, Janat B, Yazdanpanah $\mathrm{H}_{,}$ et al. (2019) Risk Associated with the Intake of Aflatoxin M1 from Milk in Iran. World Mycotoxin Journal 12(2): 191-200.

30. Flores-Flores ME, Lizarraga E, de Cerain AL, Penas EG (2015) Presence of Mycotoxins in Animal Milk: A Review. Food Control 53: 163-176.

31. Yitbarek MB, Tamir B (2013) Mycotoxines and/or Aflatoxines in Milk and Milk Products. American Scientific Research Journal for Engineering, Technology, and Sciences (ASRJETS) 4(1): 1-32.

32. Kendra DF, Dyer RB (2007) Opportunities for Biotechnology and Policy Regarding Mycotoxin Issues in International Trade. International Journal of Food Microbiology 119(1-2): 147-151.

33. Wu F (2004) Mycotoxin Risk Assessment for the Purpose of Setting International Regulatory Standards. Environ Sci Technol 38(15): 40494055. 
34. Becker-Algeri TA, Castagnaro D, de Bortoli K, de Souza C, Drunkler DA et al. (2016) Mycotoxins in Bovine Milk and Dairy Products: A Review. Journal of Food Science 81(3): R544-R552.

35. Turner PC (2013) The Molecular Epidemiology of Chronic Aflatoxin Driven Impaired Child Growth. Scientifica (Cairo). 2013: 152879.

36. Warth B, Braun D, Ezekiel CN, Turner PC, Degen GH, et al. (2016) Biomonitoring of Mycotoxins in Human Breast Milk: Current State and Future Perspectives. Chem Res Toxicol 29(7): 1087-1097.

37. Shephard GS ( 2008) Risk Assessment of Aflatoxins in Food in Africa. Food Addit Contam Part A Chem Anal Control Expo Risk Assess 25(10): 1246-1256

38. The Joint FAO/WHO Expert Committee on Food Additives (2017) Evaluation of Certain Contaminants in Food: Eighty-third Report. WHO Technical Report Series 1002. WHO.

39. EFSA (2007) Opinion of The Scientific Panel on Contaminants in the Food Chain on a Request from the Commission Related to the Potential Increase of Consumer Health Risk by a Possible Increase of the Existing Maximum Levels for Aflatoxins in Almonds, Hazelnuts and Pistachios and Derived Products. The EFSA Journal 446: 1-27.

40. Wu Q Jezkova A, Yuan Z, Pavlikova L, Dohnal V, et al. (2015) Biological Degradation of Aflatoxins. Drug Metab Rev 41(1): 1-7.

41. Gonçalves BL, Rosim RE, de Oliveria CAF, Corassin CH (2015) The in vitro Ability of Different Saccharomyces Ccerevisiae - Based Products to Bind Aflatoxin B1. Food Control 47: 298-300.

42. Kabak B, Dobson AD, Var I (2006) Strategies to Prevent Mycotoxin Contamination of Food and Animal Feed: a Review. Crit Rev Food Sci Nutr 46(8): 593-619.

43. Kim S, Lee H, Lee S, Lee J, Ha J, et al. (2017) Invited Review: Microbe-mediated Aflatoxin Decontamination of Dairy Products and Feeds. J Dairy Sci 100(2): 871-880.

44. Ciegler A, Lillehoj EB, Peterson RE, Hall HH (1966) Microbial Detoxification of Aflatoxin. Appl Microbiol 14(6): 934-939.

45. FAO/WHO (2002) Joint Working Group Report on Drafting Guidelines for the Evaluation of Probiotics in Food. London, Ontario, Canada.

46. Ahlberg SH, Joutsjoki V, Korhonen HJ (2015) Potential of Lactic Acid Bacteria in Aflatoxin Risk Mitigation. International Journal of Food Microbiology 207: 87-102.

47. Wacoo AP, Mukisa IM, Meeme R, Byakika S, Wendiro D, et al. (2019) Probiotic Enrichment and Reduction of Aflatoxins in a Traditional African Maize-Based Fermented Food. Nutrients 11(2): 265.

48. Fazeli MR, Hajimohammadali M, Moshkani A, Samadi N, Jamalifar H, et al. (2009) Aflatoxin B1 Binding Capacity of Autochthonous Strains of Lactic Acid Bacteria. J Food Prot 72(1): 189-192.

49. Pierides M, El-Nezami H, Peltonen K, Salminen S, Ahokas J (2000) Ability of Dairy Strains of Lactic Acid Bacteria to Bind Aflatoxin M1 in a Food Model. J Food Prot 63(5): 645-650.

50. El-Nezami H, Kankaanpaa P, Salminen S, Ahokas J (1998) Ability of Dairy Strains of Lactic Acid Bacteria to Bind a Common Food Carcinogen, Aflatoxin B1. Food Chem Toxicol 36(4): 321-326.

51. Kabak B, Var I (2008) Factors Affecting the Removal of Aflatoxin M1 from Food Model by Lactobacillus and Bifidobacterium Strains. Journal of Environmental Science and Health B 43(7): 617-624.

52. Sarlak Z, Rouhi M, Mohammadi R, Khaksar R, Mortazavian AM, et al (2017) Probiotic Biological Strategies to Decontaminate Aflatoxin M1 in a Traditional Iranian Fermented Milk Drink (Doogh). Food Control 71: $152-159$

53. Shetty PH, Jespersen L (2006) Saccharomyces Cerevisiae and Lactic Acid Bacteria as Potential Mycotoxin Decontaminating Agents. Trends in Food Science \& Technology 17(2): 48-55.

54. Haskard CA, El-Nezami HS, Kankaanpää PE, Salminen S, Ahokas JT (2001) Surface Binding of Aflatoxin B(1) by Lactic Acid Bacteria. Appl Environ Microbiol 67(7): 3086-3091.

55. Azab RM, Tawakkol WM, Hamad ARM, Elmagd MKA, El Agrab HM, et al. (2005) Detection and Estimation of Aflatoxin B1 in Feeds and its Biodegradation by Bacteria and Fungi. Egyp J Natl Toxins 2: 39-56.

56. Arab M, Sohrabvandi S, Mortazavian Am, Mohammadi R, Tavirani MR (2012) Reduction of Aflatoxin in Fermented Milks During Production and Storage. Toxin Reviews 31(3-4): 44-53.

57. Lahtinen SJ, Haskard CA, Ouwehand AC, Salminen SJ, Ahokas JT (2004) Binding of Aflatoxin B1 to Cell Wall Components of Lactobacillus rhamnosus Strain GG. Food Addit Contam 21(2): 158-164

58. Haskard C, Binnion C, Ahokas J (2000) Factors Affecting the Sequestration of Aflatoxin by Lactobacillus rhamnosus Strain GG. Chem Biol Interact 128(1): 39-49.

59. Bron PA, Molenaar D, de Vos WM, Kleerebezem M (2006) DNA Micro-array-based Identification of Bile-responsive Genes in Lactobacillus plantarum. J Appl Microbiol 100(4): 728-738.

60. Whitehead K, Versalovic J, Roos S, Britton RA (2008) Genomic and Genetic Characterization of the Bile Stress Response of Probiotic Lactobacillus reuteri ATCC 55730. Appl Environ Microbiol 74(6): 1812-1819.

61. Gunn JS (2000) Mechanisms of Bacterial Resistance and Response to Bile. Microbes Infect 2(8): 907-913.

62. Leverrier P, Dimova D, Pichereau V, Auffray Y, Boyaval P, et al. (2003) Susceptibility and Adaptive Response to Bile Salts in Propionibacterium Freudenreichii: Physiological and Proteomic Analysis. Applied and environmental microbiology 69(7): 3809-3818.

63. Begley M, Gahan CG, Hill C (2005) The Interaction Between Bacteria and Bile. FEMS Microbiol Rev 29(4): 625-651.

64. Hernandez-Mendoza A, Garcia HS, Steele JL (2009) Screening of Lactobacillus casei Strains for Their Ability to Bind Aflatoxin B1. Food Chem Toxicol 47(6): 1064-1068.

65. Serrano-Niño JC, Garduno AC, Mendoza AH, Applegate B, Ferruzzi MG, et al. (2013) Assessment of Probiotic Strains Ability to Reduce the Bioaccessibility of Aflatoxin M1 in Artificially Contaminated Milk Using an in vitro Digestive Model. Food Control 31(1): 202-207.

66. Charlwood J, Bryant D, Skehel JM, Camilleri P (2001) Analysis of $\mathrm{N}$-linked Oligosaccharides: Progress Towards the Characterisation of Glycoprotein-linked Carbohydrates. Biomolecular engineering 18(5): 229-240.

67. Landersjo C, Yang Z, Huttunen E, Widmalm G (2002) Structural Studies of the Exopolysaccharide Produced by Lactobacillus rhamnosus Strain GG (ATCC 53103). Biomacromolecules 3(4): 880-884.

68. Hernandez-Mendoza A, Guzman-de-Pena D, Garcia HS (2009) Key Role of Teichoic Acids on Aflatoxin B Binding by Probiotic Bacteria. J Appl Microbiol 107(2): 395-403.

69. Govaris A, Roussi V, Koidis PA, Botsoglou NA (2002) Distribution and Stability of Aflatoxin M1 During Production and Storage of Yoghurt. Food Addit Contam 19(11): 1043-1050.

70. Rasić JL, Skrinjar M, Markov S (1991) Decrease of Aflatoxin B1 in Yoghurt and Acidified Milks. Mycopathologia 113(2): 117-119.

71. Hassanin NI (1994) Stability of Aflatoxin M1 During Manufacture and Storage of Yoghurt, Yoghurt-cheese and Acidified Milk. Journal of the Science of Food and Agriculture 65(1): 31-34.

72. Brackett RE, Marth EH (1982) Association of Aflatoxin M1 with Casein. Zeitschrift für Lebensmittel-Untersuchung und Forschung 174(6): 439-441. 
73. Dosako S, et al. (1980) Hydrophobic Surface Areas and Net Changes of Vs1-6-casein and Vs1-casein: 6-casein Complex. Journal of Dairy Research 47: 123-129.

74. Tamime AY, Robinson RK (1999) Yoghurt: Science and Technology. (2 $2^{\text {nd }}$ edn), Cambridge, England: Woodhead Publishing; Boca Raton, Fla. : CRC Press.

75. Blanco, Carrion JL, Liria BA, Diaz N, et al. (1993) Behavior of Aflatoxins During Manufacture and Storage of Yoghurt. Milchwissenschaft 48 385-387.

76. Wiseman DW, Marth EH (1983) Behavior of Aflatoxin M1 in Yogurt, Buttermilk and Kefir. J Food Prot 46(2): 115-118.

77. Munksgaard L, et al. (1987) Carry Over of Aflatoxin From Cows' Feed to Milk And Milk Products. Milchwissenschaft 42(3): 165-167.

78. Van Egmond HP, Paulsch WE, Veringa HA, Schuller PL, et al. (1977) The Effect of Processing on The Aflatoxin M1content of Milk and Milk Products. Archives de l'Institut Pasteur de Tunis 54(4): 381-390.

79. Sarimehmetoğlu B, Küplülü ÖB (2004) Binding Ability of Aflatoxin M1 to Yoghurt Bacteria. Ankara Üniv Vet Fak Derg 51: 195-198.

80. el Khoury A, Atoui A, Yaghi J (2011) Analysis of Aflatoxin M1 in Milk and Yogurt and AFM1 Reduction By Lactic Acid Bacteria Used in Lebanese Industry. Food Control 22(10): 1695-1699.
81. Elsanhoty RM, Salam SA, Ramadan MF, Badr FH (2014) Detoxification of Aflatoxin M1 in Yoghurt Using Probiotics and Lactic Acid Bacteria. Food Control 43: 129-134.

82. Mohamadi Sani A, Marhamati Z, Marhamatizade MH (2014) Bio-Detoxification of Aflatoxin M1 in Kefir Using Lactobacillus Casei. BioTechnology: An Indian Journal 9: 219-224.

83. Abbes S, Salah-Abbès JB, Sharafi H, Jebali R, Noghabi KA, et al. (2013) Ability of Lactobacillus Rhamnosus GAF01 to Remove AFM1 in Vitro And to Counteract AFM1 Immunotoxicity In Vivo. J Immunotoxicol 10(3): 279-286.

84. Adibpour N, Soleimanian-Zad S, Sarabi-Jamab M, Tajalli F (2016) Effect of Storage Time and Concentration of Aflatoxin M1 on Toxin Binding Capacity of L. acidophilus in Fermented milk Product. J Agr Sci Tech 18(5): 1209-1220.

85. Ismail A, Levin RE, Riaz M, Akhtar S, Gong YY, et al. (2017) Effect of Different Microbial Concentrations on Binding of Aflatoxin M1 and Stability Testing. Food Control 73: 492-496.

86. Line JE, Brackett RE (1995) Factors Affecting Aflatoxin B1 Removal by Flavobacterium aurantiacum. J Food Prot 58(1): 91-94.

87. Peltonen K, el-Nezami H, Haskard C, Ahokas J, Salminen S (2001) Aflatoxin B1 Binding by Dairy Strains of Lactic Acid Bacteria and Bifidobacteria. J Dairy Sci 84(10): 2152-2156.

This work is licensed under Creative Commons Attribution 4.0 License

DOI: 10.19080/IJESNR.2019.21.556087
Your next submission with Juniper Publishers will reach you the below assets

- Quality Editorial service

- Swift Peer Review

- Reprints availability

- E-prints Service

- Manuscript Podcast for convenient understanding

- Global attainment for your research

- Manuscript accessibility in different formats ( Pdf, E-pub, Full Text, Audio)

- Unceasing customer service

Track the below URL for one-step submission https://juniperpublishers.com/online-submission.php 